\title{
ESCORE DE CÉLULAS SOMÁTICAS E SUA RELAÇÃO COM OS COMPONENTES DO LEITE EM AMOSTRAS DE TANQUE NO ESTADO DO PARANÁ
}

\author{
Newton Pohl Ribas', Paulo Rossi Junior', Uriel Vinicius Cotarelli de Andrade², Altair \\ Antonio Valotto ${ }^{3}$, Cassiane Pereira de Jesus', Maycon Cesar de Almeida \\ 1 UFPR \\ 2 FEPAR \\ ${ }^{3} \mathrm{APCBRH}$ \\ Correspondência: Newton Pohl Ribas: newtonribas.ufpr@gmail.com
}

RESUMO: Programas de gerenciamento de rebanhos leiteiros têm utilizado o escore de células somáticas (ECS), auxiliando na avaliação da qualidade do leite, permitindo mensurar a prevalência da mastite no rebanho. ECS é resultado da transformação logarítmica da CCS. A presente pesquisa avaliou o comportamento do ECS e suas relações com os teores de gordura, proteína, lactose e sólidos totais do leite cru de amostras de tanques provenientes de indústrias de laticínios do Estado do Paraná, analisadas pelo Laboratório da Qualidade do Leite (LQL) da Associação Paranaense de Criadores de Bovinos da Raça Holandesa (APCBRH), fruto do convênio com UFPR e McGill University. Foram analisadas 1.950 .034 amostras de leite, obtidas no período de janeiro de 2005 a abril de 2012, em dez regiões do Estado. A CCS foi determinada por citometria de fluxo e a composição centesimal pela absorção diferencial de ondas infravermelhas. Altas CCS influenciam a composição do leite, afetando sua qualidade, alterando a permeabilidade dos vasos sanguíneos da glândula mamária e reduzindo a secreção dos componentes do leite sintetizados (proteína, gordura e lactose) pela ação direta dos patógenos ou de enzimas. As médias estimadas e desvios-padrão para CCST, ECS, \% Gordura, \% Proteína, \% Lactose, \% Sólidos Totais e Idade da Amostra em dias foram: $553 \pm 545$ (x 1.000 células $/ \mathrm{mL}) ; 4,83 \pm 1,52 ; 3,74 \pm 0,69 ; 3,22 \pm 0,27 ; 4,40 \pm 0,23 ; 12,29 \pm$ 0,85 e 2,98 $\pm 1,57$ respectivamente. Das amostras analisadas, $65,95 \%$ apresentaram escore cinco ou menos. A análise dos dados foi realizada através do Método dos Quadrados Mínimos Generalizados. As correlações de Pearson entre componentes e o ECS, mostraram forte evidência estatística $(P<0,01)$, encontrando-se os seguintes valores: 0,$207 ; 0,029 ;-0,420$ e 0,039 respectivamente.

Palavras-chave: contagem de células somáticas; gordura; lactose; proteína; sólidos totais

\section{SOMATIC CELLS SCORE AND ITS RELATION WITH THE COMPONENTS OF THE MILK IN TANK SAMPLES IN THE STATE OF PARANÁ}

\begin{abstract}
Dairy management programs have been using somatic cells score of bulk tank milk (BTSCS), being helpful evaluating the quality of the milk, making it possible to measure the maintenance of mastitis on the herd. BTSCS is the result of logarithms transformations of the somatic cells count of bulk tank milk (BTSCC). This research studied the BTSCS comportment and its relations with raw milk's fat, protein, lactose and total solids in bulk tank milk samples from milk processors of the state of Paraná, Brazil, analyzed at the Milk Quality Laboratory Analysis of the Holstein Association of Paraná, the result of technical and scientific cooperation between UFPR and McGill University of Canada. Have been analyzed 1.950 .034 tank milk samples from ten regions of Paraná from January 2005 to April 2012. The BTSCS was determined by flow cytometry and percent composition by the differential absorption of infrared waves. The milk's composition is influenced by high BTSCC, which affect its quality, changing the permeability of blood vessels of the mammary gland and reducing the secretion of components of the synthesized milk (protein, fat and lactose) by the direct action of pathogens or enzymes. The estimated averages and standard deviation for BTSCC, fat $\%$, protein $\%$, lactose $\%$, total solids $\%$ and age of the sample in days were: $553 \pm 545$ (1.000 cells $/ \mathrm{mL})$; respectively. From the analyzed samples, $65,95 \%$ showed score 5 or less. The Pearson's correlations between fat $\%$, protein $\%$, lactose $\%$ and total solids $\%$ in BTSCS, showed strong statistic evidence $(P<0,01)$, finding the following results: 0,$207 ; 0,029 ;-0,420$ e 0,039 respectively.
\end{abstract}

Key Words: somatic cells count, fat; lactose; protein; total solids 


\section{INTRODUÇÃO}

A CCS do leite é um meio de diagnóstico da mastite subclínica, consagrada internacionalmente como a medida padrão para determinar a qualidade do leite. Diversos autores, tal como Monardes (1998) e Wells e Ott (1998), têm relatado que altas CCS influenciam a composição do leite, afetando sua qualidade, alterando a permeabilidade dos vasos sanguíneos da glândula mamária e reduzindo a secreção dos componentes do leite sintetizados (proteína, gordura e lactose) pela ação direta dos patógenos ou de enzimas. Interferindo no rendimento de derivados lácteos, caracterizados por diferença na textura, alteração nas características organolépticas, tempo de prateleira, estabilidade do UHT e composição do leite pasteurizado, que resultando em produtos de baixa qualidade e acarretando prejuízos para a indústria de laticínios (WELLS; OTT, 1998).

Animais com mastite sofrem ação enzimática de lipases de origem leucocitária que atua sobre a membrana dos glóbulos de gordura, expondo os triglicerídeos à ação de outras lipases, acarretando elevação da concentração de ácidos graxos livres e aparecimento da rancidez no leite (SANTOS, 2001). Pacheco (2011), estudando amostras de leite cru refrigerado em Pernambuco, registrou um coeficiente de correlação negativo de 0,20 entre CCS e Gordura do Leite. No entanto Pereira et al. (1999) observaram correlação positiva $(0,069)$ entre o teor de gordura do leite e o ECS, bem como, os teores de gordura aumentaram de 3,45 para $3,69 \%$ quando o ECS aumentou de zero (entre zero a 17.000 células $/ \mathrm{mL}$ ) para oito (entre 2.263 a 4.525 mil células $/ \mathrm{mL}$ ).

Paralelamente ao aumento das proteínas séricas no leite, ocorre diminuição na concentração de caseína, devido principalmente à degradação da caseína pelas proteases de origem bacteriana, dos leucócitos e do sangue, e também devido a sua reduzida síntese (SANTOS; FONSECA, 2002; CUNHA et al., 2008).

As mudanças na concentração de lactose durante a mastite podem ocorrer devido à passagem de lactose do leite para o sangue, que pode ser comprovado pelas elevadas concentrações no sangue e na urina de vacas com mastite. Adicionalmente, a lesão tecidual ocasionada pela mastite provoca redução da capacidade de síntese de lactose pelo epitélio glandular, o que afeta significativamente a quantidade do leite produzido. Devido - papel central da lactose como regulador osmótico do volume do leite. Silva et al. (2000), em amostras de leite de São Paulo, verificaram diminuição gradativa nos teores de lactose à medida que aumentava o ECS, diminuindo de $4,68 \%$ para $4,49 \%$. Marques, Balbinotti e Fischer (2002), na bacia leiteira de Santa Vitória do Palmar-RS, verificaram correlação negativa entre a CCS e o teor de lactose no leite. Da mesma forma, Machado, Pereira e Sarríes (2000), estudando amostras de tanque nos Estados de São Paulo e Minas Gerais, observaram diminuição nas porcentagens de lactose $(4,53$ a $4,43 \%)$ quando a CCST aumentou de 500.000 células $/ \mathrm{mL}$ para acima de 1.500 mil células $/ \mathrm{mL}$.

Bueno et al. (2005), avaliando amostras de tanque em 2002 e 2003 no Estado de Goiás, registraram que quando a CCST aumentava de 200.000 para mais de 1.000 .000 células $/ \mathrm{mL}$ os sólidos totais reduziam de $12,61 \%$ para $12,20 \%$, justificadas por alterações observadas nos teores de proteína e lactose, representando uma redução de $3,25 \%$. Também, registraram a correlação linear negativa $(0,16)$ entre a concentração de sólidos totais e o ECS. Estes resultados estão de acordo com as reduções citadas por Brito e Dias 
(1998), porém, Machado, Pereira e Sarríes (2000) e Silva, Oliveira, Galvão et al. (2000) não observaram diferenças significativas. Essa ausência de significância, segundo os autores, decorre concomitantemente com 0 aumento da concentração de gordura, que poderia mascarar o efeito da redução dos teores de proteína e lactose sobre a concentração de sólidos totais.

Todavia, outros autores têm encontrado resultados contrários aos citados acima. Machado, Pereira e Sarríes (2000), estudando amostras de tanque nos Estados de São Paulo e Minas Gerais, observaram acréscimos nas porcentagens de sólidos totais $(12,37$ a $12,30 \%)$ quando a CCST aumentou de 500.000 células/ mL para acima de 1.500 mil células $/ \mathrm{mL}$. Hartmann (1999), estudando amostras de tanque no Estado do Paraná, Santa Catarina e São Paulo, observou aumento da concentração de sólidos totais segundo o ECS, aumentando de $12,20 \%$ a $12,41 \%$ quando o ECS variou de um a sete, justificado pelo autor pelo fato da redução da produção de leite ser mais acentuada que o decréscimo da produção de gordura, ocorrendo concentração desse componente, tendo em vista a alta incidência de mastite nos rebanhos estudados. Registrou ainda correlações positivas entre os teores de sólidos totais e a CCST $(0,01)$ e com o $\operatorname{ECS}(0,02)$.

Neste trabalho foram analisados os componentes do leite (porcentagem de gordura, proteína, lactose e sólidos totais) e a CCST de amostras provenientes das indústrias de laticínios, que se utilizam dos serviços do LQL do PARLPR da APCBRH, para monitorar a qualidade do leite em atendimento ao PNMQL (IN 51, 2002 e IN 62, 2012 do MAPA).

Os objetivos do presente trabalho foram identificar os efeitos de meio ambiente (mês e ano de análise, região, idade da amostra e escore de células somáticas) que estariam influenciando as porcentagens de gordura, proteína, lactose e sólidos totais, estimando os componentes de variância para estas características em amostras de leite de tanques, bem como, caracterizar a distribuição das amostras de leite de tanques nas classes de ECS e obter as relações e correlações dos componentes do leite com ECS.

\section{MATERIAL E MÉTODOS}

Para o estudo da CCST foram utilizadas $\quad 1.950 .034 \quad$ amostras refrigeradas de leite de tanques provenientes de propriedades localizadas em 10 regiões (Noroeste Umuarama; Centro Ocidental - Campo Mourão; Norte Central - Londrina; Norte Pioneiro - Cornélio Procópio; Centro Oriental - Ponta Grossa; Oeste Cascavel; Sudoeste - Francisco Beltrão; Centro Sul - Guarapuava; Sudeste - Irati e Metropolitana de Curitiba) no Estado do Paraná (PR), analisadas no período de janeiro de 2005 a abril de 2012, pelo LQL do PARLPR da APCBRH. As amostras foram analisadas utilizando-se do equipamento Somacount $300 \AA$ (1995b), por citometria de fluxo para a contagem de células somáticas e para quantificar o percentual de gordura, proteína, lactose e sólidos totais através do equipamento automatizado Bentley 2000® (1995b), por leitura de absorção infravermelha. Concentração de sólidos totais foi obtida pelo resultado da regressão calculada pelos equipamentos citados no item anterior, simultaneamente a realização das leituras dos porcentuais de gordura, proteína, lactose e cinzas.

O ECS, resultado da transformação logarítmica da CCS (ALI e SHOOK, 1980 e SHOOK, 1982), obtida pela equação $\mathrm{ECS}=\log _{2}$ $(\mathrm{CCS} / 100)+3$. Os valores de ECS correspondentes ao intervalo de CCS de 
zero a 12.000 células/ $\mathrm{mL}$ foram forçados a serem iguais a zero, para se evitarem números negativos;

A preparação do banco de dados, triagem prévia dos dados e as análises estatísticas para porcentagens de gordura, proteína, lactose e sólidos totais e ECS foram realizadas no Departamento de Zootecnia do Setor de Ciências Agrárias da UFPR em CuritibaPR.

Segundo Hartmann (1999), Ostrensky (1999) e Paula et al. (2004), visando melhor acurácia das análises para amostras de leite de bovinos, as seguintes restrições foram impostas ao banco de dados: gordura menor que $1,5 \%$ e maior que $6,5 \%$; proteína menor que $1,5 \%$ e maior que $6,5 \%$; lactose menor que $1,5 \%$ e maior que $6,5 \%$; sólidos totais menor que $4,0 \%$ e maior que $18 \%$; idade de amostra menor que um e maior que sete dias e CCS menor ou igual a zero e maior que 4.525.000 células/ $\mathrm{mL}$.

A análise dos dados foi realizada adotando-se o programa computacional SAS® versão 9.3 (2011), cujo modelo matemático: $e_{i j k l m}$

$$
Y_{i j k l m}=\mu+M_{i}+A_{j}+R_{k}+l_{l}+E_{C} S_{m}+
$$

Em que:

$\mathrm{Y}_{\mathrm{ijklm}}=$ observação referente à porcentagens de gordura, proteína, lactose, sólidos totais, de amostras de leite de tanques, coletadas no mês i, no ano j, na região $\mathrm{k}$, com idade $\mathrm{da}$ amostra I, escore da contagem de células somáticas (ECS) $\mathrm{m}$ e erro aleatório associado a cada observação $\mathrm{e}_{\mathrm{ijk} k \mathrm{~m} \text {, onde: }}$

$\mu=$ média geral;

$\mathrm{M}_{\mathrm{i}} \quad=$ efeito do mês de análise i, sendo i = 1 (jan), 2 (fev), ..., 12 (dez);

$A_{j}=$ efeito do ano de análise j, sendo j $=2005,2006, \ldots, 2012^{*}$;

$R_{k}=$ efeito da região $k$, sendo $k=1,2, \ldots, 10$;

$l_{1}=$ efeito da idade da amostra em dias $I$, sendo $I=1,2, \ldots, 7$;
$E_{m} \quad=E C S$, sendo $m=0,1, \ldots, 8$;

$\mathrm{e}_{\mathrm{ijk \textrm {k } m}}=$ erro aleatório associado a cada observação $Y_{i j k l m}$.

*o ano de 2012 está representado apenas por amostras de leite coletadas nos quatro primeiros meses do ano.

A comparação entre médias foi realizada por meio do Teste de Tukey a $1 \%$ de probabilidade.

Para estudo das relações entre os componentes do leite (\% gordura, \% proteína, \% lactose e \% sólidos totais) e o escore de células somáticas (ECS) foram obtidos os coeficientes de correlação de Pearson.

\section{RESULTADOS E DISCUSSÃO}

As médias observadas, os respectivos desvios padrão e os coeficientes de variação da \% gordura, $\%$ proteína, \% lactose, \% sólidos totais, idade da amostra (dias), escore de células somáticas (ECS) e contagem de células somáticas (CCST), analisados no período de 2005 a 2012 encontramse na Tabela 1.

A média de CCST observada na Tabela 1 foi superior àquelas encontradas por Franks (2001) e por Godkin (1999), analisando médias da CCST em diferentes países. Franks (2001) observou a menor média na Suíça (112.000 células $/ \mathrm{ml})$ e a maior média em Israel (382.000 células $/ \mathrm{ml}$ ) e Godkin (1999), na Província de Ontário, Canadá, encontrou uma média de 250.000 células/ml.

No Brasil, Machado, Pereira e Sarríes (2000), trabalhando com número de dados menor, encontraram média e desvio-padrão para a CCST de 505.000 e 593.000 células $/ \mathrm{ml}$ respectivamente, entretanto, foram estimativas semelhantes aos valores observados neste estudo.

As médias estimadas, respectivos desvios padrão e coeficientes de variação foram para: \% gordura $(3,74 \pm 0,69 ; 17,57 \%)$, \% 

tanque no estado do Paraná

proteína $(3,22 \pm 0,27 ; 8,12 \%)$, \% de lactose $(4,40 \pm 0,23 ; 4,61 \%), \%$ de sólidos totais $(12,29 \pm 0,85 ; 6,79 \%)$, ECS $(4,83 \pm 1,52 ; 30,06 \%)$ e CCST $(553$ $\pm 545 ; 96,10 \%)$ em amostras de leite de tanques analisados no período de 2005 a 2012. A idade da amostra apresentou média de 2,98 $\pm 1,57$ dias (tabela 1 ).

\begin{tabular}{|c|c|c|c|c|c|}
\hline CARACTERÍSTICAS & N & MÉDIA & \pm & $\mathrm{DP}$ & $\mathrm{CV}(\%)$ \\
\hline$\%$ Gordura & 1.950 .034 & 3,74 & \pm & 0,69 & 17,57 \\
\hline \% Proteína & 1.950 .034 & 3,22 & \pm & 0,27 & 8,12 \\
\hline$\%$ Lactose & 1.950 .034 & 4,40 & \pm & 0,23 & 4,61 \\
\hline \% Sólidos Totais & 1.950 .034 & 12,29 & \pm & 0,85 & 6,79 \\
\hline $\mathrm{ECS}^{1}$ & 1.950 .034 & 4,83 & \pm & 1,52 & 30,06 \\
\hline $\operatorname{CCST}^{2}$ & 1.950 .034 & 553 & \pm & 545 & 96,10 \\
\hline Idade da Amostra (dias) & 1.950 .034 & 2,98 & \pm & 1,57 & - \\
\hline
\end{tabular}

O erro-padrão foi menor para o ECS, em todos os modelos estudados. Estes resultados são semelhantes aos encontrados por Shook \& Ruegg (1999), Ostrensky (1999) e Paula (2002), que observaram também, maiores $\mathrm{R}^{2}$, menores CV e menores erros-padrão com 0 uso das transformações logarítmicas para a CCST, portanto, consolidando do ponto de vista estatístico a utilização das transformações logarítmicas da CCST em ECS.

Ostrensky (1999) e Paula (2002) estudando o ECS no Estado do Paraná encontraram também resultados semelhantes ao desta pesquisa, destacando, respectivamente, 4,461 \pm 1,789 e 4,839 $\pm 1,235$, ficando caracterizado que apesar de todo 0 esforço das entidades que atuam na pecuária leiteira do Paraná, a qualidade do leite pelo padrão da CCST e ou ECS permanece inalterada nos últimos doze anos.

Os resultados encontrados neste trabalho quando comparado com países de pecuária leiteira desenvolvida são altos, refletindo pouco cuidado dos produtores com relação à sanidade da glândula mamária e à falta de estímulo por parte das indústrias em estabelecer programas de pagamento de leite por qualidade focando a CCS e ou ECS. Bem como, a média encontrada no limite superior de 500.000 células $/ \mathrm{ml}$, segundo Harmon \& Reneau (1993), estaria associado com $16 \%$ de quartos infectados nos rebanhos e com $6 \%$ de perdas na produção de leite.

A distribuição das amostras de CCST em classes de ECS estimadas nesta pesquisa encontra-se na Tabela 2. Nesta, observa-se que $65,95 \%$ das amostras se enquadram no escore cinco ou menos, resultados estão abaixo dos objetivos estabelecidos pelos serviços de controle de rebanhos leiteiros dos Estados Unidos e Canadá, que tem como meta atingir um nível em que $80 \%$ de seus rebanhos apresentem, no máximo, escore três (RIBAS, 1999).

\begin{tabular}{|c|c|c|c|}
\hline ECS & $\begin{array}{l}\text { VARIACCÁO DA } \\
\text { CCST }^{1}\end{array}$ & $\mathrm{~N}$ & $\%$ \\
\hline 0 & 0 a 17 & 30.439 & 1,56 \\
\hline 1 & 18 a 34 & 42.581 & 3,74 \\
\hline 2 & 35 a 70 & 63.934 & 7,02 \\
\hline 3 & 71 a 140 & 167.315 & 15,60 \\
\hline 4 & 141 a 282 & 384.531 & 35,32 \\
\hline 5 & 283 a 565 & 597.231 & 65,95 \\
\hline 6 & 566 a 1.130 & 454.298 & 89,25 \\
\hline 7 & 1.131 a 2.262 & 170.923 & 98,01 \\
\hline 8 & 2.263 a 4.525 & 38.782 & 100,00 \\
\hline TOTAL & & 1.950 .034 & \\
\hline
\end{tabular}

A grande frequência de amostras encontradas no ECS cinco ou menos caracteriza a importância da adoção de políticas como programas de pagamento do leite por qualidade pelas indústrias de laticínios e a implementação de limites legais previsto pela IN 62 (Brasil, 2011) do MAPA, visando redução de 600.000 células $/ \mathrm{ml}$ de 2012 para 400.000 células $/ \mathrm{ml}$ em 2015.

Os efeitos de meio ambiente, caracterizados por mês de análise, ano de análise, região, idade da amostra e (ECS), influenciaram significativamente os componentes do leite $(P<0,01)$.

$O$ efeito de ECS influenciou significativamente as quatro variáveis estudadas (\% gordura, \% proteína, \% 
lactose e \% sólidos totais) $(\mathrm{P}<0,01) . \mathrm{Na}$ tabela 3, apresentamos os coeficientes de correlação de Pearson obtidos entre os componentes do leite e o ECS.

Tabela 3 - Coeficientes de correlação de Pearson entre as porcentagens de gordura, proteína, lactose, sólidos totais e o escore de células somáticas (ECS).

\begin{tabular}{cc}
\hline Características & ECS \\
\cline { 2 - 2 } & Correlação $(r)$ \\
\hline \% Gordura & $0,207^{*}$ \\
\% Proteína & $0,029^{\star}$ \\
\% Lactose & $-0,420^{\star}$ \\
\% Sólidos Totais & $0,039^{\star}$ \\
\hline${ }^{*}(\mathrm{P}<0,01)$ &
\end{tabular}

\section{Porcentagem de gordura}

Na tabela 3, pode-se observar que a \% de gordura apresentou correlação positiva com o ECS $(0,207)$. Foi estimado que o valor esperado de gordura está relacionado com o ECS $(P<0,01)$.

$\mathrm{Na}$ tabela 4, apresentamos as relações entre o ECS variando de 0 a 8 com as respectivas médias ajustadas para porcentagem de gordura. Quando o ECS variou de zero para oito (de zero a 4.525 .000 células/ $\mathrm{mL}$ ) a porcentagem de gordura aumentou de 3,28 para $3,96 \%$, respectivamente.

Outros autores, estudando os componentes do leite, registraram também correlações médias e positivas com aumento da porcentagem de gordura do leite, entre eles, Pereira, Prada e Silva, Molon, Machado e Barancelli (1999), Machado, Pereira e Sarríes (2000), Marques, Balbinotti e Fischer (2002) e Noro (2004), justificando que com os elevados níveis de mastite nos rebanhos, a gordura pode estar concentrada no leite quando a produção é reduzida mais intensamente que a síntese de gordura.

$\mathrm{Na}$ tabela 3, observa-se que a \% proteína apresentou correlação positiva com o ECS $(0,029)$, sendo encontrada forte evidência estatística $(P<0,01)$ de que o valor esperado esteja relacionado com o ECS.

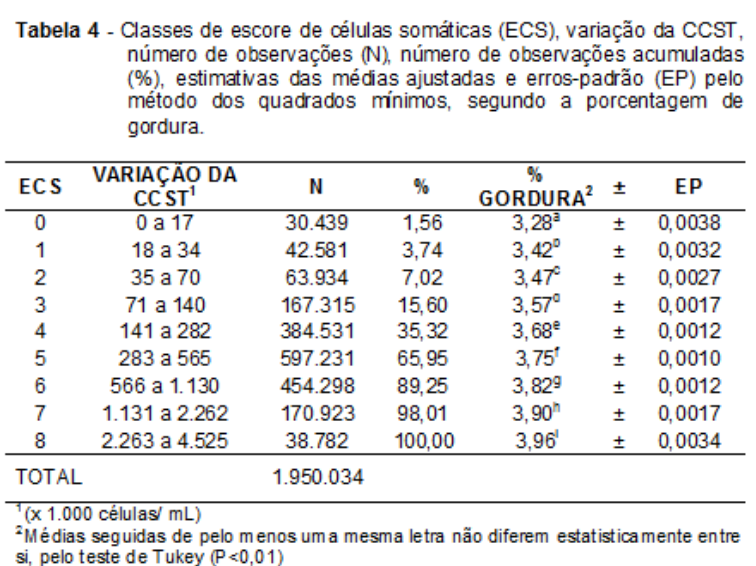

\section{Porcentagem de proteína, segundo o escore de células somáticas (ECS)}

$\mathrm{Na}$ tabela 5, apresentamos as relações entre o ECS variando de zero a oito com as respectivas médias ajustadas para \% proteína. Quando o ECS variou de zero a oito (zero a 4.525.000 células $/ \mathrm{mL}$ ) a porcentagem de proteína aumentou de 3,15 para $3,28 \%$, respectivamente.

Segundo Weaver e Kroger (1977) e NG-KWAI-HANG, Hayes, Moxley e Monardes (1982), estes resultados são justificados por infecção na glândula mamária ocasionando um aumento no $\mathrm{pH}$, mudanças na permeabilidade da membrana que separa o sangue do leite, levando a aumento do influxo de albumina e de imunoglobulinas para o interior da glândula mamária, aumentando a concentração de proteína total do leite.

No entanto, paralelamente ao aumento das proteínas séricas no leite, ocorre diminuição na concentração de caseína, devido principalmente à degradação da caseína pelas proteases de origem bacteriana, dos leucócitos e do sangue, e também devido a sua reduzida síntese justificada por Santos e Fonseca (2002) e Cunha, Molina, Carvalho, Facury Filho, Ferreira e Gentilini (2008).

Outros autores também estimaram correlações baixas e positivas, com aumento da \% proteína do leite quando o ECS variou de zero a nove, entre eles, Pereira, Prada e Silva, Molon et al. 

tanque no estado do Paraná

(1999), Marques, Balbinotti e Fischer (2002), Noro (2004), Bueno, Mesquita, Nicolau et al. (2005) e Moscon, Beltrame, Rigo et al. (2011).

\begin{tabular}{|c|c|c|c|c|c|c|}
\hline $\mathrm{ECS}$ & $\begin{array}{l}\text { VARIAÇAO DA } \\
\text { CCST }^{1}\end{array}$ & N & $\%$ & $\begin{array}{c}\% \\
\text { PROTEINA }\end{array}$ & \pm & EP \\
\hline 0 & 0 a 17 & 30.439 & 1,56 & $3,15^{\mathrm{a}}$ & \pm & 0,0015 \\
\hline 1 & 18 a 34 & 42.581 & 3,74 & $3,17^{\circ}$ & \pm & 0,0013 \\
\hline 2 & 35 a 70 & 63.934 & 7,02 & $3,21^{\circ}$ & \pm & 0,0010 \\
\hline 3 & 71 a 140 & 167.315 & 15,60 & $3,23^{\circ}$ & \pm & 0,0006 \\
\hline 4 & 141 a 282 & 384.531 & 35,32 & $3,23^{*}$ & \pm & 0,0004 \\
\hline 5 & 283 a 565 & 597.231 & 65,95 & $3.22^{\circ}$ & \pm & 0,0004 \\
\hline 6 & 566 a 1.130 & 454.298 & 89,25 & $3,23^{e g}$ & \pm & 0,0004 \\
\hline 7 & 1.131 a 2.262 & 170.923 & 98,01 & $3,24^{n}$ & \pm & 0,0007 \\
\hline 8 & 2.263 a 4.525 & 38.782 & 100,00 & $3,28^{1}$ & \pm & 0,0013 \\
\hline \multicolumn{2}{|c|}{ TOTAL } & 1.950 .034 & & & & \\
\hline
\end{tabular}

Porcentagem de Lactose, segundo o escore de células somáticas (ECS)

$\mathrm{Na}$ tabela 3, observa-se que a \% lactose apresentou correlação alta e negativa com 0 ECS $(-0,420)$, encontrado forte evidência estatística $(P<0,01)$ de que o valor esperado esteja relacionado com o ECS.

$\mathrm{Na}$ tabela 6, apresentamos as relações entre o ECS variando de 0 a 8 com as respectivas médias ajustadas para \% lactose. Quando a ECS variou de zero a oito (zero a 4.525 .000 células $/ \mathrm{mL}$ ) a porcentagem de lactose diminuiu de 4,63 para $4,14 \%$, respectivamente.

Segundo Rogers, Mitchell e Bartley (1989), Shuster, Harmon e Jackson (1991), Schukken et al. (1992a), Schaellibaum (2000) e Santos (2001), vacas com altas CCST e ECS apresentam diminuição na concentração de lactose no leite devido à passagem da mesma para o sangue, que pode ser comprovado pelas elevadas concentrações de lactose no sangue e na urina de vacas com mastite. Assim como a lesão tecidual ocasionada pela mastite provoca redução da capacidade de síntese de lactose pelo epitélio glandular, o que afeta significativamente a quantidade do leite produzido, devido ao papel central da lactose como regulador osmótico do volume do leite.

Outros pesquisadores, estudando as relações da \% lactose com CCST e ECS, encontraram resultados semelhantes a esta pesquisa, entre eles: Harmon (1994), Brito e Dias (1998), Silva, Oliveira, Galvão, Martinez, Freitas e Neiva (2000), Schaellibaum (2000), Marques, Balbinotti e Fischer (2002) e Noro (2004).

\begin{tabular}{|c|c|c|c|c|c|c|}
\hline ECS & $\begin{array}{c}\text { VARIACÁAO DA } \\
\text { CCST }^{1}\end{array}$ & N & $\%$ & $\begin{array}{c}\% \\
\text { LACTOSE }^{2}\end{array}$ & \pm & EP \\
\hline 0 & 0 a 17 & 30.439 & 1,56 & $4,63^{2}$ & \pm & 0,0011 \\
\hline 1 & 18 a 34 & 42.581 & 3,74 & $4,60^{\circ}$ & \pm & 0,0010 \\
\hline 2 & 35 a 70 & 63.934 & 7,02 & $4,56^{\circ}$ & \pm & 0,0008 \\
\hline 3 & 71 a 140 & 167.315 & 15,60 & $4,51^{d}$ & \pm & 0,0005 \\
\hline 4 & 141 a 282 & 384.531 & 35,32 & $4,46^{\mathrm{e}}$ & \pm & 0,0003 \\
\hline 5 & 283 a 565 & 597.231 & 65,95 & $4,41^{\top}$ & \pm & 0,0003 \\
\hline 6 & 566 a 1.130 & 454.298 & 89,25 & $4,34^{9}$ & \pm & 0,0003 \\
\hline 7 & 1.131 a 2.262 & 170.923 & 98,01 & $4,25^{n}$ & \pm & 0,0005 \\
\hline 8 & 2.263 a 4.525 & 38.782 & 100,00 & $4,14^{\prime}$ & \pm & 0,0010 \\
\hline \multicolumn{2}{|c|}{ TOTAL } & 1.950 .034 & & & & \\
\hline
\end{tabular}
entre si, pelo teste de Tukey $(P<0,01)$

Porcentagem de sólidos totais, segundo 0 escore de células somáticas (ECS)

As concentrações de sólidos totais apresentaram correlação baixa e positiva com o ECS $(0,039)$, demonstrando que o valor esperado está relacionado com o ECS (Tabela 4, $\mathrm{P}<0,01$ ).

$\mathrm{Na}$ tabela 7, apresentamos as relações entre o ECS variando de zero a oito com as respectivas médias ajustadas para \% sólidos totais. Quando - ECS variou de zero a oito (zero a 4.525.000 células $/ \mathrm{mL}$ ) a \% sólidos totais aumentou de 12,03 para $12,27 \%$, respectivamente.

Este aumento pode ser atribuído ao fato da redução da produção de leite ser mais acentuada que o decréscimo da produção de gordura, ocorrendo concentração desse componente, tendo em vista a alta incidência de mastite nos rebanhos estudados.

Hartmann (1999) registrou também correlação baixa e positiva, com 
aumento da \% sólidos totais do leite quando o ECS passou de zero a nove. Porém, Bueno, Mesquita, Nicolau, Oliveira, Oliveira, Neves, Mansur e Thomaz (2005) e Pacheco (2011), contrariando os resultados desta pesquisa encontraram correlações baixas e negativas.

Hartmann (1999) encontrou resultados semelhantes a esta pesquisa, ou seja, acréscimos nas \% sólidos totais, com aumento da CCST e ou ECS. Entretanto, outros pesquisadores encontraram resultados contrários a esta pesquisa, dentre eles: Brito e Dias (1998), Bueno et al. (2005) e Pacheco (2011).

\begin{tabular}{|c|c|c|c|c|c|c|}
\hline ECS & $\begin{array}{c}\text { VARIACCÃO DA } \\
\text { CCST }^{1}\end{array}$ & N & $\%$ & $\begin{array}{c}\% \\
\text { SÓLIDOS } \\
\text { TOTAIS }^{2}\end{array}$ & \pm & EP \\
\hline 0 & 0 a 17 & 30.439 & 1,56 & $12,03^{3}$ & \pm & 0,0049 \\
\hline 1 & 18 a 34 & 42.581 & 3,74 & $12,16^{\circ}$ & \pm & 0.0041 \\
\hline 2 & 35 a 70 & 63.934 & $7, \infty$ & $12,20^{\circ}$ & \pm & 0,0034 \\
\hline 3 & 71 a 140 & 167.315 & 15,60 & $12,28^{\circ}$ & \pm & 0,0022 \\
\hline 4 & 141 a 282 & 384.531 & 35,32 & $12,31^{e}$ & \pm & 0,0015 \\
\hline 5 & 283 a 565 & 597.231 & 65,95 & $12,32^{e t}$ & \pm & 0,0013 \\
\hline 6 & 566 a 1.130 & 454.298 & 89,25 & $12,30^{9}$ & \pm & 0,0015 \\
\hline 7 & 1.131 a 2.262 & 170.923 & 98,01 & $12,30^{9 n}$ & \pm & 0,0022 \\
\hline 8 & 2.263 a 4.525 & 38.782 & 100,00 & $12,27^{\text {б1 }}$ & \pm & 0,0043 \\
\hline \multicolumn{2}{|c|}{ TOTAL } & 1.950 .034 & & & & \\
\hline
\end{tabular}

\section{CONCLUSÃO}

A transformação logarítmica do CCST para ECS mostrou maior precisão nas análises estatísticas, apresentando maior coeficiente de determinação, menor coeficiente de variação e menores erros-padrão.

A grande frequência de amostras encontradas no ECS cinco ou menos $(65,95 \%)$, refletem um elevado nível de mastite nos rebanhos estudados, associado com significativa quantidade de quartos infectados e perdas na produção de leite.

O efeito do escore de células somáticas (ECS) influenciou significativamente os componentes do leite (porcentagem de gordura, proteína, lactose e sólidos totais).

Frente aos resultados encontrados, fica evidente a necessidade por parte dos produtores de reavaliarem a gestão dos programas de controle da mastite que focam a saúde da glândula mamária. As indústrias envolvidas devem também reavaliar seus programas de pagamento do leite por qualidade correlacionando componentes do leite com o escore de células somáticas (ECS).

\section{AGRADECIMENTOS}

Ao Laboratório de Análise da Qualidade do Leite do Programa de Análise de Rebanhos Leiteiros do Paraná - PARLPR da Associação Paranaense de Criadores de Bovinos da Raça Holandesa - APCBRH, fruto da cooperação técnica e científica entre a UFPR e McGill University do Canadá, pela cessão do banco de dados e pela valiosa colaboração.

Ao FUNDO PARANÁ da Secretaria da Ciência, Tecnologia e Ensino Superior, Curitiba-PR, pelo apoio financeiro através dos convênios números 01/07 e 19/07, com a Fundação da Universidade Federal do Paraná para o Desenvolvimento da Ciência, da Tecnologia e da Cultura, que possibilitaram a realização deste projeto de pesquisa junto ao Programa de Pós Graduação em Ciências Veterinárias da UFPR.

\section{NOTAS INFORMATIVAS}

A Comissão de Ética no Uso de Animais (CEUA) do Setor de Ciências Agrárias (SCA) da Universidade Federal do Paraná (UFPR) aprovou o projeto através do protocolo 024/2011. 


\section{REFERÊNCIAS}

ALI, A. K. A.; SHOOK, G. E. Na optimum transformation for matic cell concentration in milk. Journal of Dairy Science, Champaign, v.63, p. 487-490, 1980.

BENTLEY INSTRUMENTS. 1995a. Bentley 2000 Operator's Manual. Chaska. p.77.

BENTLEY INSTRUMENTS. 1995b. Somacount 300 Operator's Manual. Chaska. p.12.

BRASIL. Ministério da Agricultura e do Abastecimento, Instrução Normativa. Portaria $n$. 51, de 18 de setembro de 2002. Diário Oficial da República Federativa do Brasil, Brasília, DF, n.321, 20 set. 2002.

BRASIL. Ministério da Agricultura e do Abastecimento, Portaria n. 62, de 30 de dezembro de 2011. Diário Oficial da República Federativa do Brasil, Brasília, DF, n.251, 30 dez. 2011.

BRITO, J. R. F.; DIAS, J. C. A qualidade do leite. Juiz de Fora: Embrapa/Tortuga, 1998.

BUENO, V. F. F.; MESQUITA, A. J.; NICOLAU, E. S. et al. Contagem celular somática: relação com a composição centesimal do leite e período do ano no Estado de Goiás. Ciência Rural, Santa Maria, v.35, n.4, p.848-854, jul./ago. 2005.

CUNHA, R. P. L.; MOLINA, L. R.; CARVALHO, A. U. et al. Mastite subclínica e relação da contagem de células somáticas com número de lactações, produção e composição química do leite em vacas da raça Holandesa. Arquivo Brasileiro de Med. Veterinária e Zootecnia, Belo Horizonte, v.60, n.1, p. 9-24, 2008.

FRANKS, B. International Milk quality. 2001. Disponível em:

<http://www.2nzdairy.co.nz:82/suppliernews/july 2001.pdf>. Acesso em: 24/03/2012.

GODKIN, A. Monitoring and controlling mastitis: progress in Ontario. In: NATIONAL MASTITIS COUNCIL REGIONAL MEETING, 1999, Waterloo. Proceddings... Madison: National Mastitis Council, 1999. p. 1-9.

HARMON, R. J.; RENEAU, J. K. Factors affecting somatic cell counts in milk. In: NATIONAL MASTITIS COUNCIL ANNUAL MEETING, 32., 1993, Arlington. Proceedings... Madison: National Mastitis Council, 1993.
HARMON, R. J. Physiology of mastitis and factors affecting somatic cell counts. Journal of Dairy Science, v. 77, n.7, p.2103-2112, 1994.

HARMON, R. J. Somatic cell counts: Mysths vs reality. In: NATIONAL MASTITIS COUNCIL REGIONAL MEETING, 37., 1998, Bellevue. Proceedings... Madison: National Mastitis Council, 1998b. p.40-50.

HARTMANN, W. Sólidos totais em amostras de leite de tanques. $56 \mathrm{f}$. Dissertação

(Mestrado em Ciências Veterinárias) - Curso de Pós-Graduação em Ciências Veterinárias, Setor de Ciências Agrárias, Universidade Federal do Paraná, Curitiba, 1999.

MARQUES, L. T.; BALBINOTTI, M.; FISCHER, V. Variação da composição química do leite de acordo com a contagem de células somáticas. In: CONGRESSO PANAMERICANO DE QUALIDADE DO LEITE E CONTROLE DE MASTITE, 2., 2002, Ribeirão Preto. Anais... 1 CD ROM.

MACHADO, P. F.; PEREIRA, A. R.; SARRÍES, G. A. Composição do leite de tanques de rebanhos brasileiros distribuídos segundo sua contagem de células somáticas. Revista Bras. de Zootecnia, v.29, n.6, p.1883-1886, 2000.

MONARDES, H. Programa de pagamento de leite por qualidade em Québec, Canadá. In: SIMPÓSIO INTERNACIONAL SOBRE QUALIDADE DO LEITE, 1., 1998, Curitiba. Anais... Curitiba, 1998. p. 40-43.

MOSCON, L. A.; BELTRAME, R. T.; RIGO, T.; QUIRINO, C. R. Caracterização da Contagem de Células Somáticas em uma Propriedade no Município de Colatina - ES. Revista de Veterinária e Zootecnia, Rio de Janeiro, v.18, n.4, Supl.3, p.1064-1067, 2011.

NORO, G. Fatores ambientais que afetam a produção e a qualidade do leite em rebanhos ligados a cooperativas gaúchas. $92 \mathrm{p}$.

Dissertação (Mestrado em Ciências Veterinárias) - Universidade Federal do Rio Grande do Sul, Porto Alegre, 2004.

NG-KWAI-HANG, F. K.; HAYES, J. F.; MOXLEY, J. E. et al. Environmental influences on protein content and composition of bovine milk. Journal of Dairy Science, v.65, n.10, p. 1933-1998, 1982.

OSTRENSKY, A. Efeitos de ambientes sobre a contagem de células somáticas no leite de vacas da raça holandesa no Paraná. 114 f. 
Dissertação (Mestrado em Ciências Veterinárias) - Curso de Pós-Graduação em Ciências Veterinárias, Setor de Ciências Agrárias, Universidade Federal do Paraná, Curitiba, 1999.

PACHECO, M. S. Leite cru refrigerado do Agreste Pernambucano: caracterização da qualidade e do sistema de produção. 87 p. Dissertação (Mestrado em Ciências e Tecnologia de Alimentos) - Programa de PósGraduação em Ciência e Tecnologia de Alimentos, Universidade Federal Rural de Pernambuco, Recife: 2011.

PAULA, M. C. Contagem de células somáticas em amostras de leite de tanques. $45 \mathrm{f}$. Dissertação (Mestrado em Ciências Veterinárias) - Curso de Pós-Graduação em Ciências Veterinárias, Setor de Ciências Agrárias, Universidade Federal do Paraná, Curitiba, 2002.

PAULA, M. C.; RIBAS, N. P.; MONARDES, H. G. et al. Contagem de Células Somáticas em Amostras de Leite. Revista Brasileira de Zootecnia, v.33, n.5, p.1303-1308, 2004.

PEREIRA, A. R.; PRADA E SILVA, L. F.; MOLON, L. K. et al. Efeito do nível de células somáticas sobre os constituintes do leite I gordura e proteína. Brazilian Journal Veterinary Research and Animal Science, São Paulo, v.36, n.3, p.429-433, 1999.

RIBAS, N. P. Importância da contagem de células somáticas para a saúde da glândula mamária e qualidade do leite. In: INTERLEITE: SIMPÓSIO INTERNACIONAL SOBRE PRODUÇÃO INTENSIVA DE PRODUÇÃO DE LEITE, 4., 1999, Caxambu. Anais... São Paulo, 1999. p. 77-87.

ROGERS, S. A.; MITCHELL, G. E.; BARTLEY, J.P. The relationship between somatic cell count, composition and manufacturing properties of bulk milk 4. nonprotein constituents.

Australian Journal of Dairy Technology, Highett, v.44, n.2, p.53-56, 1989.

SANTOS, M. V. Contagem de células somáticas e qualidade do leite e derivados. In: SIMPÓSIO INTERNACIONAL SOBRE PRODUÇÃO INTENSIVA DE LEITE, 5., 2001, Belo Horizonte. Anais... Belo Horizonte, 2001. p.115-127.

SANTOS, M. V.; FONSECA, L. F. L. Contagem de células somáticas e qualidade industrial do leite. In: CURSO ONLINE SOBRE A QUALIDADE DO LEITE, 2., 2002. Disponível em: <http://www.milkpoint.com.br>. Acesso em: 20/04/2012.

SAS® System for Linear Models, version 9.3. Cary: SAS institute, 2011.

SCHÄELLIBAUM, M. Efeitos de altas contagens de células somáticas sobre a produção e qualidade de queijos. In: SIMPÓSIO INTERNACIONAL SOBRE QUALIDADE DO LEITE, 2., 2000, Curitiba. Anais... Curitiba, 2000. p. 21-26.

SCHUKKEN, Y. H.; LESLIE, K. E.; WEERSINK, A. et al. Ontario bulk milk somatic cell reduction program. 1. Impact on somatic cell counts and milk quality. Journal of Dairy Science, Champaign, v.75, n.12, p.3352-3358, 1992a.

SHOOK, G. E. Aproaches to summarizing somatic cell count which improve interpretability. In: NATIONAL MASTITIS COUNCIL ANNUAL MEETING, 21., 1982, Pennsylvanis.

Procedings... Madison: National Mastitis Council, 1982. p. 150-166.

SHOOK, G. E.; RUEGG, P. Geometric mean somatic cell counts: what they are; what they do. In: NATIONAL MASTITIS COUNCIL ANNUAL MEETING, 38., 1999, Arlington. Proceedings... Madison: NMC, 1999. p. 93-100.

SHUSTER, D. E., HARMON, R. J., JACKSON, J. A. et al. Suppression of milk production during endotoxin-induced mastitis. Journal of Dairy Science, v.74, n.11, p.3763-3774, 1991.

SILVA, A. R. P.; OLIVEIRA, A. I. G.; GALVÃO, R. J. D. et al. Avaliação do desempenho produtivo de rebanhos da raça Pardo-Suiça no estado de São Paulo. Ciência e

Agrotecnologia, v.24, n.2, p.458-467, 2000.

SMITH, K. L.; HOGAN, J. S. Milk quality: a worldwide perspective. In: NATIONAL MASTITIS COUNCIL ANNUAL MEETING, 37., 1998, St. Louis. Proceedings... Madison: National Mastitis Council, 1998. p. 3-9.

WEAVER, J. C.; KROGER, M. Protein, casein, and non casein protein percentages in milk with haigh somatic cells counts. Journal of Dairy Science, v.60, n.6, p.878-881, 1977.

WELLS, S. J.; OTT, S. L. What is the current milk quality in the US? In: NATIONAL MASTITIS COUNCIL ANNUAL MEETING, 37., 1998, St. Louis. Proceedings... Madison: National Mastitis Council, 1998. p. 10-18. 